\title{
Incidence of cutaneous and subcutaneous tumors of dogs from Baghdad city: clinical, cytological and histopathological features
}

\author{
I.J. Lafta ${ }^{*}$ and H.H. Alabbody ${ }^{2}$ \\ ${ }^{1}$ Department of Microbiology, College of Veterinary Medicine, ${ }^{2}$ Market Research Center and Consumer Protection, \\ University of Baghdad, Baghdad, Iraq, Email: 1ĳlafta@gmail.com, ${ }^{2}$ hudaalabbody@gmail.com
}

(Received April 4, 2019; Accepted May 13, 2019)

\begin{abstract}
The present study was conducted to estimate the incidence, clinical findings, cytological and histopathological characteristics of spontaneously occurring skin neoplasms in dogs. A total of 40 grossly suspected cases of cutaneous and subcutaneous tumors were gathered during the period from July 2016 to August 2018 from male and female dogs in Baghdad city. Dogs with skin neoplasia revealed various clinical signs, and their ages were older than 5 years to 15 years. German shepherd 30\% followed by Terrier dogs $25 \%$ were more influenced than other breeds. Concerning tumor features, the majority of neoplasms had solitary lesion $70 \%$, regular shapes $65 \%$ with black color $55 \%$. The tumors frequently occurred on fore-limbs and abdomen, and $80 \%$ of them lasted for 1-6 months. Cytological examination was valuable for initial evaluation of benign and malignant tumors. Its results were confirmed by the histopathology, in which the majority of neoplasms sized more than $5 \mathrm{~cm}$ and grade I. Nine different types of skin neoplasms were recognized, while $65 \%$ of them were malignant, the others were benign. Squamous cell carcinoma and adenocarcinomas were the most common comprising $35 \%$ and $25 \%$, respectively.
\end{abstract}

Keywords: Dogs, Skin tumor, Clinical signs, Cytology, Histopathology

Available online at http://www.vetmedmosul.com, (C) 2020, College of Veterinary Medicine, University of Mosul.

This is an open access article under the CC BY 4.0 license (http://creativecommons.org/licenses/by/4.0/).

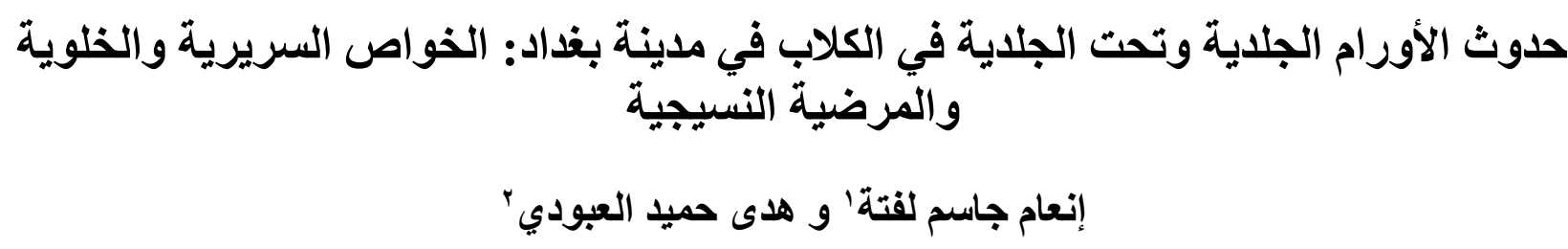

' فرع الاحياء المجهرية ، كلية الطب البيطري، `مركز بحوث السوق وحماية المستهلك، جامعة بغداد، بغداد، العراق

أجريت الدر اسة الحالية لتقييم أور ام الجلد التي حدثت تلقائيا لكلاب موجودة في مدينة بغداد من ناحية نسب الحدوث و والعباد العلامات السريرية

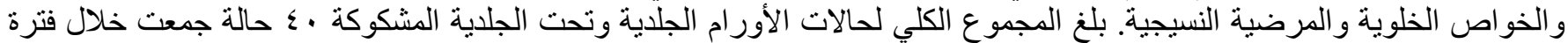

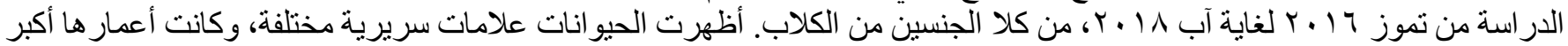

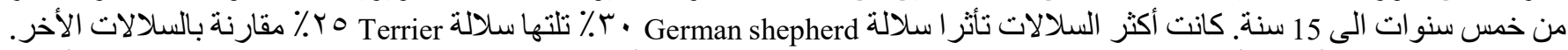

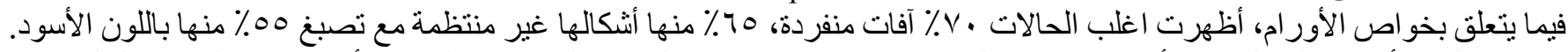

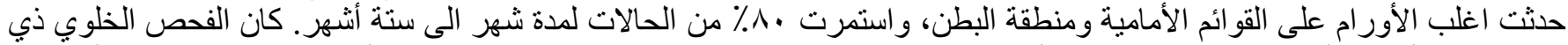

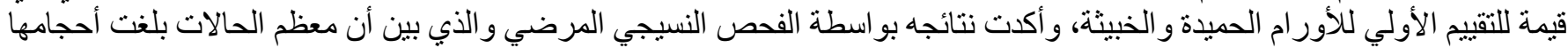

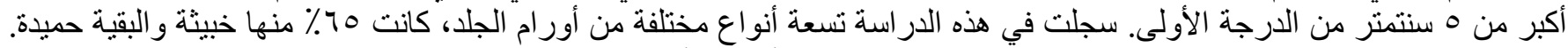

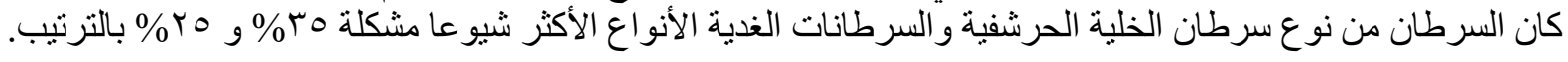




\section{Introduction}

Domestic dogs Canis familiaris are the most frequently and naturally affected with cancers (1), particularly skin tumors, compared to humans (2); canine acquires neoplasms twice as frequently as humans (3). Skin is the largest organ of the body (4), it harbors between 9.5 and $51 \%$ of all neoplasms in dogs. A wide variety of tumor types can occur in the skin, subcutaneous tissue, and adnexa (appendages) (1). The incidence of neoplasms in dogs is not fully known and is difficult to ascertain as well (2). As a big organ, the skin is exposed to various oncogenic factors, including ultraviolet rays (5), which can cause localized tumors, such as squamous cell carcinoma (6). Ionized radiation has an oncogenic effect based on the dose, type of radiation and the way of its release. Chemical carcinogens as well as certain types of food that contain natural chemicals have the capability to cause DNA damage and cell alterations. In addition, some DNA and RNA viruses, known as tumor viruses, have been proved to cause cancer in infected cells (7). Genetic factors and environmental risk factors are also of significant importance to skin neoplasia. Furthermore, the skin is composed of a considerable number of cells in constant renewal, consequently, it is more prone to occurrence of disorders in the coding genes, leading to mutations (2).

Naturally occurring or spontaneous tumors in dogs are of special interest for comparative studies since these tumors occur in various outbred populations that live in close proximity to humans (8). Thus, these animals are affected by similar environmental factors that could cause chronic diseases and cancer in human (9). Moreover, dogs' tumors have gained more attention because of the fondness and increased awareness among their owners towards the sufferings and pain caused to these speechless animals (10). Therefore, dogs are considered as recommended models owing to their relatively high cancer susceptibility and due to many behavioral resemblances (11). The prevalence of cancer in dogs is possibly different among various regions. It has been found that there are regional variations in the occurrence rate and type of neoplasms that affect dogs (12). Variances in the prevalence, predilection sites, sex, age and breed of dog have been shown in the studies performed in Australia (13-15), the USA (16), the United Kingdom (17), Greece (18) and South Africa (4). Part of these differences might be attributed to exposure of dog populations to different environmental carcinogens as well as discrepancies in breed popularity (12). Understanding the existence of different types of canine cancers in a defined geographical area brings benefits to veterinary physicians in terms of improving their diagnosis and taking correct decisions regarding treatment (19), and this is the key reason for performing this type of clinical studies (18). In Iraq, a very limited number of clinical and histopathological studies have been conducted on canine prostate cancers (20), mammary gland tumors $(21,22)$, and tumors in different body regions (23).

Therefore, the current study aimed to estimate the incidence of cutaneous and subcutaneous tumors in 40 dogs at Baghdad city, to assess age, sex, breed, and body site distribution of canine skin neoplasms. Adding to applying cytological examination by fine needle aspiration and histopathological classification of skin tumors, with analyzing the mitotic index using $\mathrm{Ki}-67$, a biomarker for cell proliferation.

\section{Materials and methods}

\section{Study animals}

Forty virgin non-spayed dogs, referred from the Teaching Animal Hospital at Adan Square as well as various private veterinary clinics at Baghdad, Iraq, were diagnosed as having cutaneous or subcutaneous tumors. The duration of the study was two years from July 2016 to August 2018.

\section{Case history and physical examination}

Case history was reported for all dogs under study, including: age, gender, breed, spaying history and location of skin tumor in the body. Lymph nodes, such as prescapular, axillary and inguinal lymph nodes were palpated for enlargement as well as for unilateral or bilateral involvement. The lesions were also grossly examined and described for numbers, size, location, presence of erythema, ulceration, necrosis and bleeding. Furthermore, the occurrence of other diseases and the nature of discharges, i.e. bloody, serous or serosanguineous was documented. Radiographs were captured for some cases in order to look for masses or metastasis inside the animal's body.

\section{Tumor staging and grading}

Tumor stage refers to size and/or extent (reach) of the original (primary) tumor and whether or not cancer cells have spread in the body. While tumor grade is the description of a tumor based on how abnormal the tumor cells look under a microscope. The stage of the tumor, at the time of surgery, was classified based on the tumor's size into: T1 (mass $<3$ $\mathrm{cm}$ in the greatest dimension), T2 $(>3 \mathrm{~cm}$ but $<5 \mathrm{~cm})$ or T3 $(>5 \mathrm{~cm})$, according to the guidelines of the World Health Organization (WHO) described by (24). With respect to tumor grading, neoplasms were classified into grade I: well differentiated cells and grade II with moderately differentiated cells (25).

\section{Cytology examination}

Fine needle aspiration cytology was done under aseptic conditions according to the technique adopted from (26). A needle of 24 gauge was used for this method, in which a material enough for cytological examination was obtained 
via introducing and withdrawing the needle alone for two to three passes without forcing pressure by suction. Smears were stained with Hematoxylin and Eosin (HE). Both fine needle aspiration cytology and biopsy were interpreted independently of one another.

\section{Biopsies collection}

Informal consent was taken from dogs' owners before surgery. Routine surgical procedures were performed by a specialist veterinary surgeon to remove the suspected masses. The tissue biopsies had been fixed in 10\% neutral buffered formalin and embedded in paraffin.

\section{Histopathological studies}

The formalin fixed and paraffin embedded samples were sectioned into sections of 4 to $5 \mu \mathrm{m}$ thickness. The slides were stained with HE following the method of (27), and the tissue sections were examined under the light microscope. Based on the changes seen under the microscope, the tumors were classified into benign or malignant. The characters taken into account included: presence of a capsule around the tumor, anisocytosis (unequal size of red blood cells), anisokaryosis (the sizes of cells' nuclei, which are larger than normal; determined as mild/moderate or severe), cellularity of the neoplasm, invasion to adjacent tissues and intratumoral necrosis.

\section{Immunohistochemistry (IHC)}

The IHC assay was performed by using the standard streptavidin-biotin LSAB kit (Dako, Denmark) to investigate the protein expression of Ki-67. Briefly, formalin-fixed and paraffin-embedded samples' blocks were cut into $5 \mu \mathrm{m}$ slices, which were mounted onto glass slides. The slides were then de-waxed by xylene and rehydrated in $99 \%$ and $95 \%$ of ethanol. In order to destroy endogenous tissue peroxidase activity, the slides were treated with a mixture of $\mathrm{H}_{2} \mathrm{O}_{2}$ in methanol (peroxidase blocking reagent) at room temperature for 10 minutes. Later, the slides were rinsed in running tap water for 5 minutes. Subsequently, antigen retrieval was performed by putting the slides into goblin jar containing 1:10 retrieval solution. The jar was incubated in a water bath at $95^{\circ} \mathrm{C}$ for half an hour to uncover hidden antigenic sites. The slides were immersed in $10 \mathrm{mM}$ citrate buffer, and then left to cool at room temperature for 20 minutes. Meanwhile, 10x tris buffer saline (TBS) was made by adding $10 \mathrm{ml}$ of TBS to $90 \mathrm{ml}$ distilled water (DW), into which the slides were left for 5 minutes to maintain the $\mathrm{pH}$ within a relatively narrow range. Afterwards, the slides were put in a humidifying chamber, and circles were drawn around tissue sections using hydrophobic barrier pen.

Prior to adding the primary anti-human Ki-67 antibody (clone MIB-1, Dako, Denmark), IHC procedure was optimized. Later, the slides were incubated with the above antibody diluted to 1:100 using EnVision ${ }^{\mathrm{TM}}$ FLEX antibody diluent (DM830, Dako, Denmark) at $4{ }^{\circ} \mathrm{C}$ overnight. The excessive antibody amounts were removed by washing slides with TBS for 5 minutes. The next step involved adding the biotinylated secondary antibody to the slides for 30 minutes. During this time, the Avidin-Biotinylating enzyme complex $(\mathrm{ABC})$, which is a peroxidase reagent, was made and left to stand at room temperature till use. The slides were then washed with TBS for 5 minutes to get rid of excess secondary antibody, and the $\mathrm{ABC}$ was placed on the sections for $10 \mathrm{~min}$, followed by washing with TBS for 5 minutes.

Diaminobenzidine (DAB; peroxidase substrate) was put onto the sections for 10 minutes to convert the peroxidase to a colored product. The slides were then rinsed with DW for $2 \mathrm{~min}$, and the counter dye hematoxylin was used to stain the nuclei for 1 minute. The excessive dye was removed in a bath of running tap water for $1 \mathrm{~min}$, the slides were further washed with DW for $2 \mathrm{~min}$, and passed through series of gradual alcohols $(70,90,95$, and $99 \%)$ for 3 minutes each and mounted with xylene for 15 minutes. Ultimately, cover slips $(22 \times 32 \mathrm{~mm})$ were fixed using DPX and left to dry. The slides were examined under the light microscope by a pathologist. The score of Ki-67 was calculated based on the average percentage of positively stained nuclei among the tumor cells. The scoring method of (28) was followed, in which a score of 0 was given to $<5 \%$ positive cells, score 1 to $5-10 \%$ positive cells, score 2 to $10-20 \%$ positive cells, score 3 to 20 $30 \%$ positive cells, score 4 to $30-50 \%$ positive cells, and score 5 to $>50 \%$ positive cells.

\section{Results}

\section{Clinical findings}

Dogs with skin tumor displayed a variety of symptoms. These symptoms were diverse based on the tumor's location and how far it has metastasized. The tumors looked as raised and hairless masses around fore and hind limbs, head, neck, chest, back, abdomen, tail and shoulders. Other symptoms included: redness of skin, loss of pigment, itching, scaly skin, skin ulcers or lesions around eyes, nose or mouth, bleeding, delayed wound healing and enlarged lymph nodes (Figure 1). The systemic clinical signs involved: depression, mild fever, anorexia, irregular heart rhythm, irregular blood pressure and coughing.

\section{Age, sex and breed of the affected dogs}

The animals' ages varied from less than one year to 20 years. The highest percentage $45 \%$ of the affected animals was seen in the age group $>5-10$ years, whereas the lowest percentage $5 \%$ was in the age group $<1$ year. The age group of $>10-15$ years constituted $35 \%$ of the cases, and $15 \%$ of neoplasms were seen within the group of $>15-20$ years. Concerning animals' sex, the affected females slightly exceeded the numbers of males (22 versus 18 , respectively). Regarding breeds, the German shepherd dogs were more 
prone to develop skin tumors, and accounted for $30 \%$ of cases, followed by Terrier $25 \%$ and the Belgian Malinois $20 \%$. However, other breeds also showed neoplasms, such as Pointer, Labrador and cross breed. Police and military dogs showed higher percentage $75 \%$ than pet dogs $25 \%$ (Table 1 ).

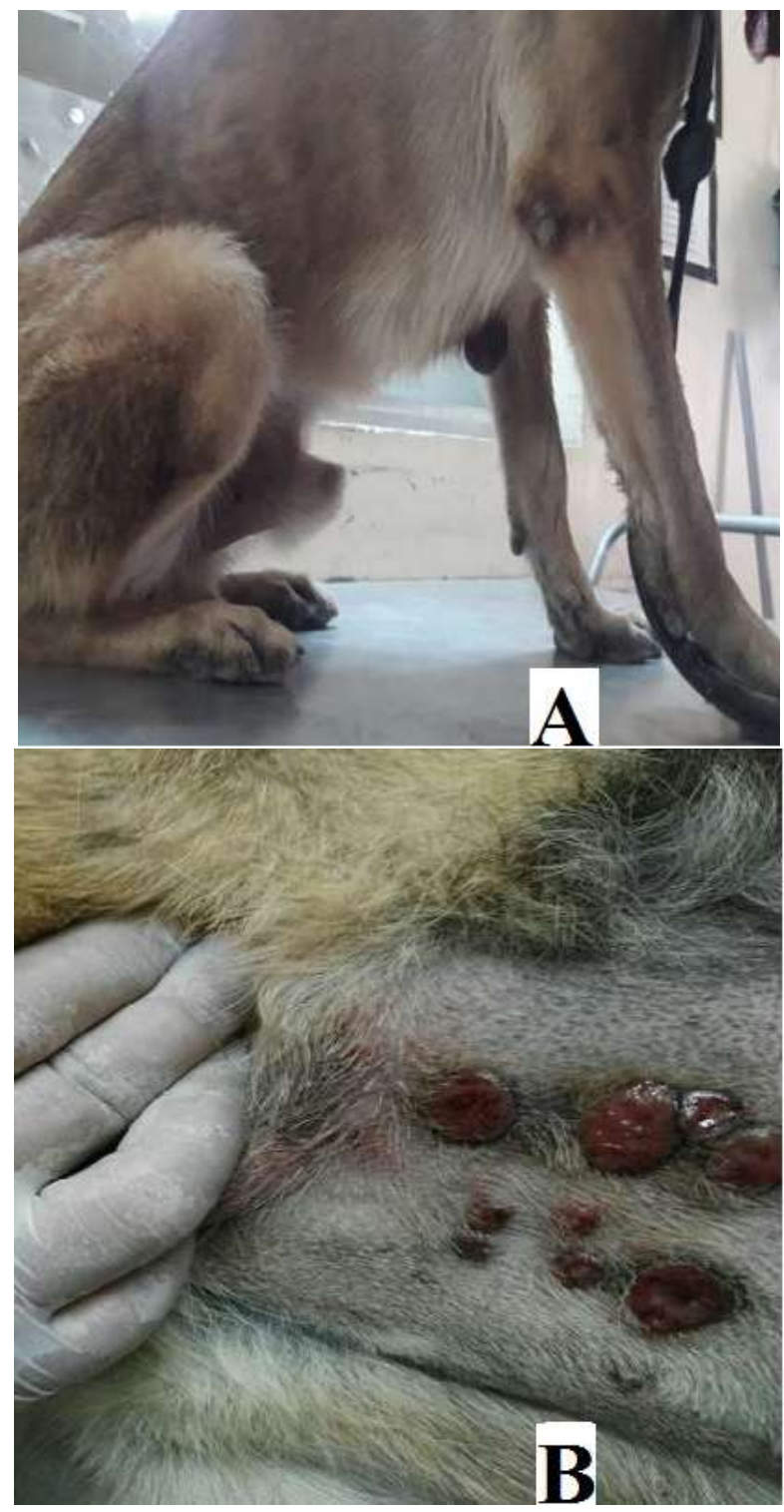

Figure 1: Male dogs of German shepherd breed suffer from skin tumors: A- a dog aged 8 years shows multi-lumps in several parts of the body, the largest one is in the chest and has the same size as ping pong, flexible in touch with folded skin. The second lump is on the right fore limb (elbow joint), and the third one is on the wrist area of the left hind limb. BA dog aged 7 years has multi-masses on the skin of abdomen, these masses appear congested and ulcerated with various shapes and slightly elevated from the skin surface.

\section{Gross characteristics of skin tumors}

The data pertaining to tumor shape, color, texture, site and duration of its existence on the skin are summarized in Table 2. The highest percentage $70 \%$ of the masses were solitary compared with only $30 \%$ multiple. Significant number of the neoplasms showed regular spherical shapes, and approximately half of the cases were black in color. Concerning texture, similar number of tumors were either solid or soft (each 16 out of 40 ), whereas the least were fibrous in nature $(8 / 40)$. The most frequent tumors were observed on the fore-limbs and abdomen (30 and 25\%, respectively). Eighty percent of the masses had developed before 1-6 months prior to animal examination, while the other cases had occurred a year ago.

Table 1: Age, sex, breed and life style of the affected dogs

\begin{tabular}{llcc}
\hline Variable & Categories & No. & $\%$ \\
\hline \multirow{3}{*}{ Age } & $<1$ year & 2 & 5 \\
& $>5-10$ years & 18 & 45 \\
& $>10-15$ years & 14 & 35 \\
& $>15-20$ years & 6 & 15 \\
\hline Total & & 40 & 100 \\
\hline Sex & Male & 18 & 45 \\
& Female & 22 & 55 \\
\hline Total & & 40 & 100 \\
\hline Breed & Belgian Malinois & 8 & 20 \\
& German shepherd & 12 & 30 \\
& Pointer & 4 & 10 \\
& Terrier & 10 & 25 \\
& Labrador & 2 & 5 \\
& Cross breed & 4 & 10 \\
\hline Total & & 40 & 100 \\
\hline Life style & Police and military & 30 & 75 \\
& Pet & 10 & 25 \\
\hline Total & & 40 & 100 \\
\hline
\end{tabular}

\section{Histological classification and cytology of skin tumors}

Histological classification, staging and grading of the skin neoplasms are summarized in Table 3 . Of the 40 cases analyzed, 14 were benign 35\%, $25(62.5 \%)$ were diagnosed as grade I, and only one case $2.5 \%$ as grade II tumors. Seventy percent of the tumors belonged to stage III as their sizes were more than $5 \mathrm{~cm}$. Nine different types of malignant and benign neoplasms were recognized for the skin. Of these, SCC was the most common comprising $35 \%$, followed by $15 \%$ adenocarcinoma, $10 \%$ to each of tubulo-papillary adenocarcinoma, cutaneous histiocytoma and lipoma, and $5 \%$ to each of carcinoid tumor with SCC, fibro-adenoma, leiomyoma and fibroma. Table 4 shows the number of benign and malignant tumors as well as their prognosis. 
Table 2: Size, shape, color, texture, location and duration of skin neoplasms

\begin{tabular}{|c|c|c|c|}
\hline Variable & Categories & No. & $\%$ \\
\hline \multirow[t]{2}{*}{ Lesion } & Multiple & 12 & 30 \\
\hline & Solitary & 28 & 70 \\
\hline Total & & 40 & 100 \\
\hline \multirow{4}{*}{ Tumor shape } & Regular & 26 & 65 \\
\hline & Irregular & 4 & 10 \\
\hline & Oval & 8 & 20 \\
\hline & Papillae & 2 & 5 \\
\hline Total & & 40 & 100 \\
\hline \multirow{3}{*}{ Tumor texture } & Solid & 16 & 40 \\
\hline & Soft & 16 & 40 \\
\hline & Fibromata & 8 & 20 \\
\hline Total & & 40 & 100 \\
\hline \multirow{5}{*}{ Colors } & Red & 8 & 20 \\
\hline & Grey & 4 & 10 \\
\hline & Black & 22 & 55 \\
\hline & White & 4 & 10 \\
\hline & Yellow & 2 & 5 \\
\hline Total & & 40 & \\
\hline \multirow[t]{2}{*}{ Duration } & $1-6$ months & 32 & 80 \\
\hline & $7-12$ months & 8 & 20 \\
\hline Total & & 40 & 100 \\
\hline \multirow{8}{*}{$\begin{array}{l}\text { Anatomic location of } \\
\text { the tumor }\end{array}$} & Fore-limb & 6 & 30 \\
\hline & Hind-limb & 1 & 50 \\
\hline & Face & 2 & 10 \\
\hline & Neck & 1 & 5 \\
\hline & Back & 1 & 5 \\
\hline & Tail & 2 & 10 \\
\hline & Abdomen & 5 & 25 \\
\hline & Chest & 2 & 10 \\
\hline Total & & 40 & 100 \\
\hline
\end{tabular}

The sections in Figure 2A show the adenocarcinoma mitotic figures, epithelial cells with hyperchromatic nuclei. Tubulo-papillary adenocarcinoma, type of adenocarcinoma, is arranged in finger like projections. Concerning cutaneous histiocytoma, it is a benign epitheliotropic neoplasm composed of intra-epidermal dendritic antigen-presenting cells (APC) also called Langerhans cells. This type showed a sheet of round cells with bean shaped folded nuclei and eosinophilic cytoplasm with mitotic figures, while the cells at peripheral areas were loosely arranged (Figure 2B). Regarding lipoma, it is a benign lump composed of fat surrounded by a membrane. On the other hand, leiomyoma was also noticed with fascicles of spindle cells overlap with each other. With respect to fibroma sections, they demonstrated fibroblast proliferation with crisscross bundles along with whorl formation. The sections of fibro-adenoma showed neoplastic masses comprising of tubules lined by columnar cells with round nuclei, also fibrous connective tissue around the ducts was seen. Squamous cell carcinoma sections invaded deep dermis forming thick cellular islands and irregular cords of squamous cells with keratinization towards the centers developing cell nests and keratin pearl, which are characteristic features of SCC (Figures 2C and 2D). Concerning cytology, it correlated with histopathology in most of the tested cases. Figures 3A \& B are examples of performing FNAC smear from a skin lipoma.

Table 3: Histological classification, staging and grading of the skin neoplasms

\begin{tabular}{llcc}
\hline Parameter & \multicolumn{1}{c}{ Feature } & $\begin{array}{c}\text { No. } \\
\text { animals }\end{array}$ & $\%$ \\
\hline Tumor & 0 & 14 & 35 \\
grade & Grade I & 25 & 62.5 \\
& Grade II & 1 & 2.5 \\
\hline Total & & 40 & 100 \\
\hline Tumor & T1: $<3 \mathrm{~cm}$ & 6 & 15 \\
stage & T2: $3-5 \mathrm{~cm}$ & 6 & 15 \\
& T3: $>5 \mathrm{~cm}$ & 28 & 70 \\
\hline Total & & 40 & 100 \\
\hline \multirow{4}{*}{ Tumor } & SCC & 14 & 35 \\
& Adenocarcinoma & 6 & 15 \\
& Tubulo-papillary adenocarcinoma & 4 & 10 \\
type & Lutaneous histiocytoma & 4 & 10 \\
& Cipoma & 4 & 10 \\
& Fibroadenoma & 2 & 5 \\
& Fibroma & 2 & 5 \\
& Leiomyoma & 2 & 5 \\
Total & & 2 & 5 \\
\hline
\end{tabular}

Table 4: The numbers of benign and malignant tumors and their prognosis

\begin{tabular}{llcc}
\hline & Categories & No. & $\%$ \\
\hline Malignancy & Benign & 14 & 35 \\
& Malignant & 26 & 65 \\
\hline Total & & 40 & 100 \\
\hline \multirow{3}{*}{ Prognosis } & Lived $>18$ months & 14 & 35 \\
& Lived $>12$ months & 11 & 27.5 \\
& Lived $>6$ months & 14 & 35 \\
& Died $<6$ months & 1 & 2.5 \\
\hline Total & & 40 & 100 \\
\hline
\end{tabular}



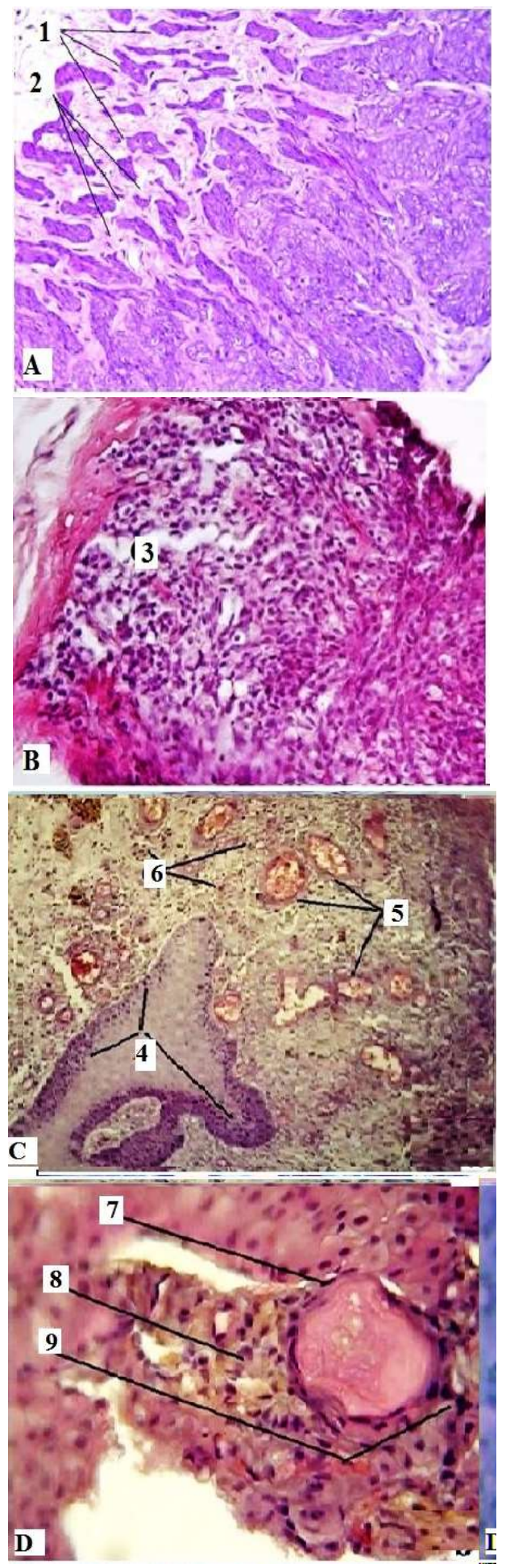

Figure 2A. Adenocarcinoma section: (1) Hyperchromatic, pleomorphic and more eosinophilic cells, especially apocrine cells. (2) Basophilic myoepithelial cells (HE x100). 2B.
Cutaneous histiocytoma section: (3) Tumor cells are arranged in cords and nests with numerous mitotic cells and acidophilic cytoplasm. The histiocytes possess round to ovoid nuclei or twisted and folded nuclei with moderately abundant cytoplasm forming intra-epidermal nests (HE $x 200)$. 2C. Histopathological examination of the skin with SCC: (4) Hyperplasia of the stratified squamous epithelium, which shows elongated dermal papillae. (5) Congested blood vessels. (6) Inflammatory cells infiltration in the dermal layer (HE x100). 2D. Squamous cell carcinoma section: (7) Irregular masses of epidermal cells that surround large amount of keratin forming what is called horn pearls. (8) Concentric layer of hyperchromatic squamous cells. (9) Extending the tumor cells into the dermal layer (HE x400).

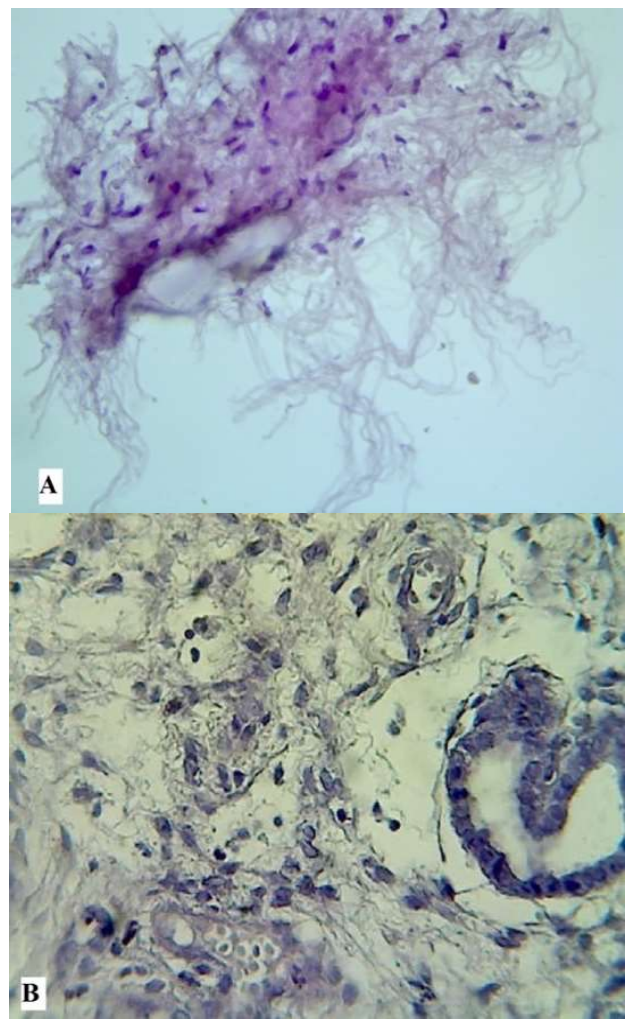

Figure 3: Fine-needle aspiration smear from a skin of a dog. A: Skin lipoma (HE x200). B: Cross sectional field from lipoma shows spindle chromatin nucleus, parallel arrays of bland spindle cells, mature adipocytes, ropey collagen bundles with myxoid background (HE x400).

\section{Immunohistochemistry}

The Ki-67 protein showed mainly nuclear staining, however, cytoplasmic staining was also occasionally seen (Figure 4F). Although only nuclear staining is considered positive, and most samples had score 2 . 


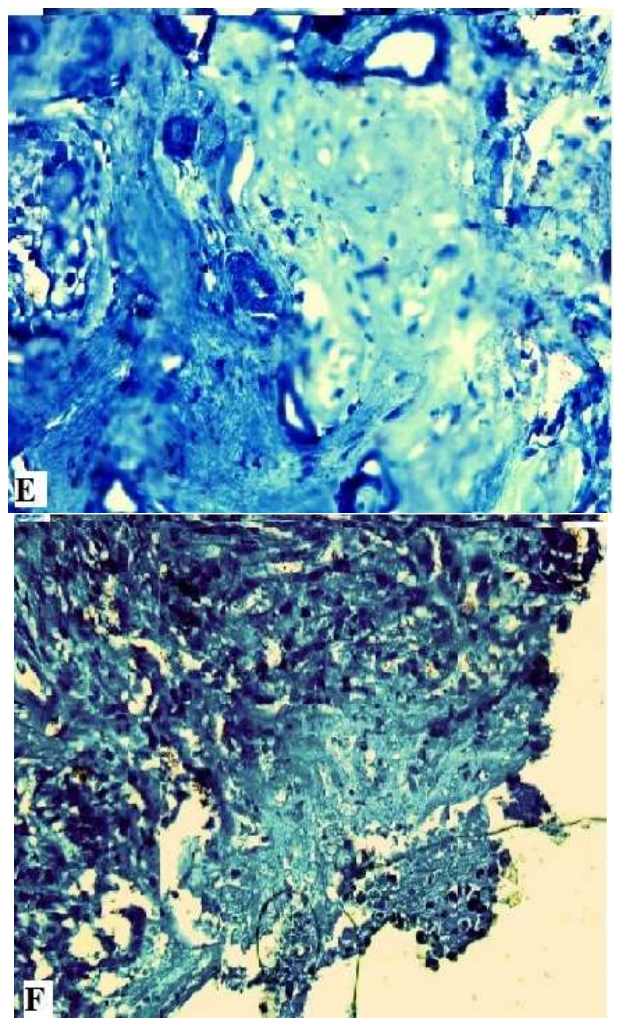

Figure 4: Immunohistochemistry staining of Ki-67 of skin. E: Benign tumor shows no Ki-67 staining F: Malignant tumor areas reveal highly variable stained nuclei, with overall protein expression of Ki-67 score $2(10 \%-20 \%)$ positive cells (x400).

\section{Discussion}

Skin is an organ that provides protection for all body parts, and it is divided into three layers: the epidermis, the dermis and the subcutaneous layer. It has been reported that sunlight is involved in the development of skin neoplasms, however, several other etiological factors can also cause this disease, including: trauma, the presence of pigmented cells, chemical exposure, genetic susceptibility and inflammation, which may be associated with the etiology (29).

In this study, throughout two years, only 40 dogs from Baghdad city suffered from cutaneous and subcutaneous tumors. In contrast, higher incidences of skin and subcutaneous neoplasms have been reported in many countries (12). The relatively low incidence of canine cancers, generally, in Iraq compared to other countries may be due to decreased awareness among dogs' owners, absence of official documentation regarding animal cancers, along with inaccurate diagnosis. Other reasons could be attributed to different climate and geographical locations (10).

Our data reveal that dogs with skin tumors showed various clinical signs, including local and systemic signs. Canine cancers are associated with diverse clinical signs, which can cause a problem to the veterinarian in making correct diagnosis and prescribing the right therapy (13). In addition, our findings are consistent with other researchers who observed necrosis and hemorrhage in all skin tumors. The hemorrhage was attributed either to the presence of heparin in the granules of mast cells, or due to the surgery via the handling and degranulation of tumors. These injuries, e.g. necrosis, edema, and hemorrhage are not statistically correlated with histological classification of tumors (30).

In this study, skin tumors were mainly reported in older dogs. Around $45 \%$ of the dogs aged $>5-10$ years, and $35 \%$ $>10-15$ years. According to Merlo et al (31), the critical period to cancer onset in dogs is 6 to 10 years old. This suggests that older ages predispose dogs to develop neoplasms, this was also reported by many authors Kaldrymidou et al; Costa et al; Hargis et al $(18,30,32)$. However, in the present study, only two cases were reported in dogs less than one year of age. This might be because of reduced immunity, hormonal imbalance, inadequate elimination and detoxifying process, and more exposure to carcinogenic agents $(10,33)$.

About the sex of animals, our data demonstrated that there is a slight difference in cancer incidence in females and males $55 \%$ and $45 \%$, respectively. These results are similar to other studies that reported no significant difference related to sex, such as the findings of Pinto and co-workers (34) who noticed $54 \%$ females versus $46 \%$ males developed cancers, while the study of Furlani et al (35) found 57\% males than $43 \%$ females were affected.

The most affected breed in this study was German shepherd followed by Terrier and Belgian Malinois. By contrast, other studies revealed different breeds to be the most commonly affected with skin tumors, such as Boxer, Pitbull, and Poodle (2). While Nishiya and co-authors (9) stated that the predisposed breeds included Scottish Terrier, Poodle, Golden Retriever, Dachshund, and others. Higher incidences of cutaneous and subcutaneous neoplasms have also been reported in several other breeds $(36,37)$. This discrepancy in the affected breeds might not be due to breed predisposition, but is probably because of the presence of more population of these breeds in the area studied as well as environmental influences, particularly UV exposure, which is responsible for the enhancement of some types of skin tumors in certain breeds (38). Concerning tumor features, the vast majority of tumors $65 \%$ in this study sized $5 \mathrm{~cm}$ in diameter. Tumor size is of importance because it has been found that dogs with tumors less than $4 \mathrm{~cm}$ or $6 \mathrm{~cm}$ in diameter had long survival times following complete surgical removal (39). Our findings show that $70 \%$ of tumors had solitary lesions, and 26 out of 40 tumor masses characterized by regular shapes. With respect to the location of skin tumors, our data show that the most common sites 
were the skin of fore-limbs and abdomen. These results are partly similar to the findings of Natividade et al (40) who found limbs to be the primary site, followed by scrotum.

In the current study, cytology examination using FNAC was used for skin neoplasms because it is safe, cheap, rapid, easy, less invasive, valuable and useful technique in differentiating benign from malignant tumors $(41,42)$. It has been used successfully to diagnose many lesions, among which melanoma, SCC and basal cell carcinoma (43). However, this technique has some limitations, such as low yield in some of the cases (41), representability of samples and inability to classifying the nature of metastatic cutaneous nodules (42). Therefore, based on the cytology followed by histopathological confirmation, the skin tumors were classified in the present study. Thirty tumors belonged to grade I and 10 cases to grade II were diagnosed, and most cases were classified under stage T3. Nine types of tumors were reported here, the most common was SCC followed by adenocarcinomas. Similar to our data, SCC was popular in the studies of Er and Sutton (15) as well as Sivaseelan et al $(15,44)$. These tumors adding to fibro-adenoma are malignant neoplasms, and together accounted for $65 \%$ of all tumors in the present research. In the study of Tostes and coworkers (2), approximately $58 \%$ of the skin neoplasms were malignant. The high malignancy reported in our study can be related to environmental factors and the late diagnosis of these neoplasms. In addition, the high incidence of SCC in our findings may be correlated to the long periods for which these dogs stay outdoors exposed to high rates of UV rays of the sun, vehicle exhaust, TNT, other carcinogens or X-ray from sonar used in police check points. By contrast to our data, low percentage $37.5 \%$ of malignant tumors were registered by Bostock (17). In addition, other authors $(1,45)$ also observed high prevalence of benign tumors. The prevalence of different histological types of tumors differs among the reports published in various regions. In comparison with our data, mast cell tumor was the most frequent type in many studies $(12,15,18,38)$. This difference in the prevalent tumor type could be due to breed differences or other environmental predisposing factors (12).

The last part of the study was determining the proliferation index by Ki-67 immunostaining. The protein $\mathrm{Ki}-67$ is expressed in the cell nucleolus (46) throughout all phases of the cell cycle, i.e. G1, S, G2 and M except G0, this makes it of prognostic value in certain types of cancers (47). Furthermore, this mitotic marker has been shown to correlate with tumor progression, metastasis as well as reduced overall survival $(48,49)$, adding to its low cost and comfortable evaluation (40). Consequently, Ki-67 expression was evaluated in the current study, which revealed sections of a heterogeneous Ki-67 staining, with some areas of malignant tumors showed highly stained nuclei, while no staining was seen in the benign sections. The Ki-67 staining further confirmed the histopathological examination, in which most of tumorous samples of this study were in situ (localized, not invasive), therefore, most stained slides were negative to this marker.

\section{Conclusion}

It can be concluded from this study that most skin neoplasms either cutaneous or subcutaneous of dogs in Baghdad are malignant. Although the reported tumors were not aggressive if they were compared with other types of neoplasia. Still more attention has to be paid for canine cancers in Iraq as a whole where many areas had been subjected to carcinogenic war ordnance. The data of the current report can help veterinarians throughout Iraq to diagnose and later treat canine tumors urgently based on the cases reported in this study.

\section{Acknowledgment}

The authors would like to thank National Cancer Research Center, University of Baghdad, for their collaboration.

\section{References}

1. Bronden LB, Eriksen T, Kristensen AT. Mast cell tumors and other skin neoplasia in Danish dogs-data from the Danish Veterinary Cancer Registry. Acta Vet Scand. 2010; 52:6. $\mathrm{http}: / / \mathrm{www}$.actavetscand.com/content/52/1/6.

2. Tostes RA, Branco A, Cestari F, Caleffo T, Viott A. Retrospective study of canine cutaneous neoplasia. Arch Vet Sci. 2017;22(1):71-80. http://dx.doi.org/10.5380/avs.v22i1.49290.

3. Rungsipipat A, Suryasootcharee B, Ousawaphlangchi L, Sailasuta A, Thanawongnuwech R. Neoplasms in dogs in Bangkok. Thailand J Vet Med. 2003;33:59-66 .

4. Bastianello SS. A survey on neoplasia in domestic species over a 40year period from 1935 to 1974 in the Republic of South Africa. VI. Tumors occurring in dogs. Onderstepoort J Vet Res. 1983;50:199-220.

5. Fabbrocini G, Triassi M, Mauriello MC, Torre G, Annunziata MC. Epidemiology of skin cancer: role of some environmental factors. Cancers. 2010;2:1980-1989. https://doi:10.3390/cancers2041980.

6. Kelsey JL, Moore AS, Glickman LT. Epidemiologic studies of risk factors for cancer in pet dogs. Epidemiol Rev. 1998; 20:204-217. https://doi.org/10.1093/oxfordjournals.epirev.a017981.

7. Todorova I. Prevalence and etiology of the most common malignant tumors in dogs and cats. Bulgarian J Vet Med. 2006;9(2):85-88 .

8. Madewell BR. Neoplasms in domestic animals: a review of experimental and spontaneous carcinogenesis. Yale J Biol Med. 1981;54:111-125.

9. Nishiya AT, Massoco CO, Felizzola CR, Perlmann E, Batschinski K. Comparative aspects of canine melanoma. Vet Sci. 2016;3. http://doi:10.3390/vetsci3010007.

10. Kashyap DK, Tiwari SK, Giri DK, Dewangan G, Sinha B. Cutaneous and subcutaneous tissue neoplasms in canines: Occurrence and histopathological studies. African J Agri Res. 2013;8(49):6569-6574.

11. Khanna C, Lindblad K, Vail D, London C, Bergman P. The dog as a cancer model. Nat Biotechnol. 2006; 24: 1065-1066. https://doi.org/10.1038/nbt0906-1065b.

12. Mukaratirwa S, Chipunza J, Chitanga S, Chimonyo M, Bhebhe E. Canine cutaneous neoplasms: prevalence and influence of age, sex and site on the presence and potential malignancy of cutaneous neoplasms 
in dogs from Zimbabwe. $\mathrm{J}$ Afr Vet Assoc. 2005;76:59-62. https://doi.org/10.4102/jsava.v76i2.398.

13. Ladds PW, Kraft H, Sokale A, Trueman KF. Neoplasms of the skin of dogs in tropical Queensland. Aust Vet J. 1983;60:87-88.

14. Rothwell TL, Howlett CR, Middleton DJ, Griffiths DA, Duff BC. Skin neoplasms of dogs in Sydney. Aust Vet J. 1987;64:161-164.

15. Er JC, Sutton RH. A survey of skin neoplasms in dogs from the Brisbane region. Aust Vet J. 1989;66:225-227.

16. Brodey RS. Canine and feline neoplasia. Adv Vet Sci Comp Med. 1970;14:309-354.

17. Bostock DE. Neoplasms of the skin and subcutaneous tissues in dogs and cats. Br Vet J. 1986;142:1-19.

18. Kaldrymidou H, Leontides L, Koutinas AF, Saridomichelakis MN, Karayannopoulou M. Prevalence, distribution and factors associated with the presence and the potential for malignancy of cutaneous neoplasms in 174 dogs admitted to a clinic in northern Greece. J Vet Med Physiol Pathol Clin Med. 2002; 49:87-91. https://doi.org/10.1046/j.1439-0442.2002.jv408.x.

19. Roudebush P, Allen TA, Dodd CE, Novotny BJ. Application of evidence-based medicine to veterinary clinical nutrition. J Am Vet Med Assoc. 2004; 224: 1765-1771. https://doi.org/10.2460/ javma.2004.224.1766.

20. Hussin AM. Histological study of prostate in adult indigenous Iraqi dogs. J Entomol Zool Stud. 2016;4(3):224-227 .

21. Abdullah MA, Al-Mufty BI, Yasin MI, Hassan NJ. Clinical and histopathological study of mammary tumors in foreign dogs breeds in Kurdistan region of Iraq. Bas J Vet Res. 2014;1(1):1 1-19.

22. Alabbody HH, Lafta IJ. Clinical pathology and immuno-histochemistry of mammary tumors from military and pet dogs in Iraq. Online J Vet Res. 2018;22(7):547-560.

23. Alabbody HH, Alwan MJ, Zenad MM, Walia AA. Clinical and histopathological study on dog's tumors in Iraq. Iraqi $\mathrm{J}$ Sci. 2017;58(383C):1617-1630.

24. Sorenmo KU, Kristiansen VM, Cofone MA, Shofer FS, Breen AM. Canine mammary gland tumors; a histological continuum from benign to malignant; clinical and histopathological evidence. Vet Comp Oncol. 2009;7:162-172. https://doi.org/10.1111/j.1476-5829.2009.00184.x.

25. Patnaik AK, Ehler WJ, MacEwen EG. Canine cutaneous mast cell tumor: Morphologic grading and survival time in 83 dogs. Vet Pathol. 1984;21:469-474.

26. Daskalopoulou D, Maounis N, Kokalis G, Liodandonaki P, Belezini E. The role of fine needle aspiration cytology in the diagnosis of primary skin tumors. Arch Anat Cytol Pathol. 1993;41(2):75-81.

27. Bancroft JD, Stevens A. Theory and practice of histological techniques. $3^{\text {rd }}$ ed. Edinburgh: Churchill Livingstone; 1990. 113-305 p.

28. Ma X, Wu Y, Zhang T, Song H, JV H. Ki67 proliferation index as a histopathological predictive and prognostic parameter of oral mucosal melanoma in patients without distant metastases. J Cancer. 2017;8:3828-3837. https://dx.doi.org/10.7150\%2Fjca.20935.

29. Dzutsev A, Goldszmid RS, Viaud S, Zitvogel L, Trinchieri G. The role of the microbiota in inflammation, carcinogenesis, and cancer therapy. Eur J Immunol. 2015;45:17-31. https://doi.org/10.1002/eji.201444972.

30. Costa MC, Aprígio Silva, AD, Moreira TA, Gundim LF, Medeiros AA. Prevalence and epidemiological and histopathological features of canine cutaneous mast cell tumors in Uberlandia, Brazil. Acta Vet Brno. 2017;86:189-193. https://doi.org/10.2754/avb201786020189.

31. Merlo DF, Rossi L, Pellegrino C, Ceppi M, Cardellino U. Cancer incidence in pet dogs: Findings of the animal tumor registry of Genoa, Italy. J Vet Intern Med. 2008; 22: 976-984. https://doi.org/10.1111/j.1939-1676.2008.0133.x.
32. Hargis AM, Ihrke PJ, Spangler WL, Stannard AA. A retrospective clinicopathologic study of 212 dogs with cutaneous hemangiomas and hemangiosarcoma. Vet Pathol. 1992;29:316-328.

33. Gamlem H, Nordstoga K, Glattre E. Canine neoplasia-introductory paper. APMIS. 2008: 5-18. https://doi.org/10.1111/j.16000463.2008.125m2.x.

34. Pinto JP, Teixeira LB, Santos AR. Estudo histopatológico e histoquímico de mastocitomas na região de Espírito Santo do Pinhal. Rev Acad. 2007;5:265-276.

35. Furlani JM, Daleck CR, Vicenti FA, Nardi AB, Pereira GT. Mastocitoma canino: Estudo restrospectivo. Ci Ani Bras. 2008;9:242250.

36. Wey N, Kohn B, Gutberlet K, Rudolph R, Brunnberg L. Mammary tumors in the bitch: Clinical follow up study 1995-1997. Vet Bull. 1999;69:8395.

37. Singh R, Mohindroo J, Banga HS, Singh SS, Kansal SK. Occurrence of neoplasms in canines. Indian J Vet Pathol. 2004;28(1):54-57.

38. Pakhrin B, Kang MS, Bae IH, Park MS, Jee H. Retrospective study of canine cutaneous tumors in Korea. J Vet Sci. 2007;8:229-236. http://doi: 10.4142/jvs.2007.8.3.229.

39. Kuznetsova LA, Kruchkov DV, Fominutes AV, Minenok AA, Kuleshova OA. Comparative characteristics of methods of treatment of melanoma in dogs. Russ Vet J Small Domest Wild Anim. 2009;4:2833 .

40. Natividade FS, Castro MB, Silva AS, Galera PD. Survival analyses and prognostic markers in canine cutaneous mast cell tumors. Pesqui Vet Bras. 2014; 34: 874-884 .https://doi.org/10.1590/S0100736X2014000900012.

41. Kassi M, Kasi PM, Afghan AK, Marri SM, Kassi M. The role of fineneedle aspiration cytology in the diagnosis of basal cell carcinoma. ISRN Dermatol. 2012;2012 .https://doi.org/10.5402/2012/132196.

42. Patel S, Mahadevappa A, Manjunath GV. Fine needle aspiration cytology of papulonodular lesions of skin: A study of 50 cases. J Clin Diagn Res. 2016; 10: EC09-EC13. https://doi.org/10.7860/JCDR/2016/22953.9107.

43. Layfield LJ, Glasgow BJ. Aspiration biopsy cytology of primary cutaneous tumors. Acta Cytol. 1993;37:679-688.

44. Sivaseelan S, Sasikala M, Sumithra A, Balasubramanium GA. Incidence of neoplasm in domestic animals. Indian Vet J. 2009;86:416417 .

45. Graf R, Pospischil A, Guscetti F, Meier D, Welle M. Cutaneous tumors in Swiss dogs: Retrospective data from the Swiss canine cancer registry 2008-2013. Vet Pathol. 2018; 55:809-820. https://doi.org/10.1177/ 0300985818789466.

46. Rahmanzadeh R, Hüttmann G, Gerdes J, Scholzen T. Chromophore assisted light inactivation of pKi67 leads to inhibition of ribosomal RNA synthesis. Cell Prolif. 2007; 40: 422-430 .https://doi.org/10.1111/ j.1365-2184.2007.00433.x.

47. Koseoglu RD, Sezer E, Eyibilen A, Aladag I, Etikan I. Expressions of $\mathrm{p} 53$, cyclinD1 and histopathological features in basal cell carcinomas. J Cutan Pathol. 2009;36:958-965. https://doi.org/10.1111/j.16000560.2008.01204.x.

48. Batinac T, Zamolo G, Coklo M, Hadzisejdic I, Stemberger C. Expression of cell cycle and apoptosis regulatory proteins in keratoacanthoma and squamous cell carcinoma. Pathol Res Pract. 2006;202:599-607. https://doi.org/10.1016/j.prp.2006.04.004.

49. Vaisanen A, Kuvaja P, Kallioinen M, Turpeenniemi T. A prognostic index in skin melanoma through the combination of matrix metalloproteinase-2, Ki67, and p53. Hum Pathol. 2011;42:1103-1111. https://doi.org/10.1016/j.humpath.2010.11.013. 